\section{Clinical comparison of sevoflurane and isoflurane when administered with nitrous oxide for surgical procedures of intermediate duration}

Christina Campbell MB ChB, Michael L. Nahrwold MD, Deborah D. Miller RN, MSN
The purpose of this study was to compare the haemodynamic effects and emergence times of anaesthesia with sevoflurane with those of isoflurane when the agents were administered with nitrous oxide to adult inpatients (ASA I and II) undergoing surgery of at least an hour in duration. Fifty patients were randomly assigned to receive either 0.65 minimum alveolar concentration (MAC) (1.3\%) sevoflurane or $0.65 M A C(0.8 \%)$ isoflurane together with $60 \%$ nitrous oxide following induction with thiopentone, fentanyl, and succinylcholine. Systemic blood pressure and heart rate trends were similar for both groups for the duration of anaesthesia. However, differences in systolic blood pressure measurements were noted at one minute afier incision $(99 \pm 3 \mathrm{mmHg}$, mean $\pm S E$, in the sevoflurane group compared with $109 \pm 4 \mathrm{mmHg}$ for isoflurane), and at emergence (125 $\pm 3 \mathrm{mmHg}$ for sevoflurane, $134 \pm 3 \mathrm{mmHg}$ for isoflurane), and in diastolic blood pressure measurements at five minutes afier intubation (64 $12 \mathrm{~mm} \mathrm{Hg}$ for sevoflurane, $73 \pm 3 \mathrm{mmHg}$ for isoflurane). Recovery of response to com-

Key words

ANAESTHETICS, VOLATILE: isoflurane, sevoflurane; ANAESTHETICS, GASES: nitrous oxide.

From the Department of Anesthesia, Indiana University School of Medicine. Work was performed at Indiana University Medical Center, Indianapolis, Indiana.

Supported in part by a grant from Abbott Laboratories, Abbott Park, IL.

Address correspondence to: Dr. Christina Campbell, Dept. of Anesthesia, Fesler Hall 204, Indiana University Medical Center, 1120 South Drive, Indianapolis, Indiana 46202-5115. Accepted for publication 16th June, 1995. mand was more rapid afier discontinuation of sevofluranenitrous oxide ( $9.9 \pm 1.1 \mathrm{~min}$ ) than after isoflurane-nitrous oxide (13.9 $\pm 1.3 \mathrm{~min}$ ). Despite earlier emergence, patients who had received sevoflurane did not request postoperative analgesia sooner. We conclude that the purported advantages of sevoflurane, namely haemodynamic stability and rapid emergence, can be expected even when the agent is administered at 0.65 MAC (1.3\%) in nitrous oxide to a typical adult surgical population undergoing procedures of intermediate duration $(2.3$ $\pm 0.2 \mathrm{hr}$.

Cette étude compare les effets hémodynamiques de l'anesthésie au sévoflurane et ses effets sur la durée du réveil avec les effets de lisoflurane quand ces agents sont administrés avec du protoxyde d'azote chez des adultes hospitalisés ( $A S A$ I et II) soumis à une intervention d'une durée minimale de une heure. Cinquante patients sont repartis au hasard pour recevoir soit du sévoflurane à $0,65 \mathrm{MAC}(1,3 \%)$ soit de lisoflurane à $0,65 \mathrm{MAC}(0,8 \%)$ dans un mélange de $\mathrm{N}_{2} \mathrm{O}$ à $60 \%$ après une induction au thiopentone, fentanyl et succinylcholine. La pression artérielle systémique et la fréquence cardiaque ont suivi des tendance indentiques dans les deux groupes pendant la durée de l'anesthésie. Cependant, des valeurs différentes de pression artérielle systolique sont enregistrées une minute après lincision $(99 \pm 3 \mathrm{mmHg} \pm E T$ avec le sévoflurane comparativement à $109 \pm 4 \mathrm{mmHg}$ avec l'isoflurane) et au moment du réveil (125 $\pm 3 \mathrm{~mm} \mathrm{Hg}$ avec le sévoflurane, $134 \pm 3 \mathrm{~mm} \mathrm{Hg}$ avec l'isoflurane). Le retour de la réponse aux ordres verbaux était plus rapide après l'arrêt du sévoflurane- $\mathrm{N}_{2} \mathrm{O}(9,9 \pm 1,1$ min). Malgré un réveil plus rapide, les patients qui avaient reçu le sévoflurane niont pas eu besoin d'analgésique plus précocement. Les auteurs concluent que les avantages présumés du sévoflurane, dont la stabilité hémodynamique et le réveil rapide, devraient être manifestes quand l'agent est administré à 0,65 $M A C(1,3 \%)$ avec du $\mathrm{N}_{2} \mathrm{O}$ à une population chirurgicale typique subissant des interventions de durée intermédiaire $(2,3 \pm 0,2 \mathrm{~h})$. 
The volatile anaesthetic sevoflurane has yet to be made commercially available in North America. Concerns over the potential for toxicity from breakdown products and biotransformation appear to have stalled its introduction into clinical practice. ${ }^{1}$ The drug does, however, have several characteristics which, at least theoretically, would be advantageous when compared with other volatile anaesthetics. Owing to a relatively low blood-gas coefficient of 0.69 , rapid induction of and emergence from anaesthesia would be expected. Since sevoflurane is perhaps the least irritant to the respiratory tract of any of the halogenated anaesthetics, it would appear particularly attractive for paediatric practice. In addition, there is both animal and human evidence that sevoflurane is remarkably devoid of untoward haemodynamic effects, ${ }^{2-6}$ maintains organ blood flow, ${ }^{7}$ and produces minimal sensitization of the myocardium to catecholamines. ${ }^{8}$

It is of note that these data were, for the most part, obtained from studies performed on either healthy volunteers or carefully screened populations of ASA I patients. Thus, it is not well documented how sevoflurane's purported benefits extrapolate to the usual clinical situation. For example, can haemodynamic stability and more rapid emergence still be expected when concentrations of $<1 \mathrm{MAC}$ are combined with nitrous oxide and administered to an average surgical patient population? Accordingly, we compared the haemodynamic effects and emergence times of $0.65 \mathrm{MAC}$ sevoflurane with those of $0.65 \mathrm{MAC}$ isoflurane when administered with nitrous oxide to adult inpatients undergoing a variety of elective surgical procedures, all expected to last longer than one hour.

\section{Methods}

\section{Subjects}

After institutional review board approval, written informed consent was obtained from eligible adult ASA I, II, and III patients undergoing surgical procedures of at least one hour duration and requiring hospitalization for at least $24 \mathrm{hr}$. Participants were randomly assigned to receive either sevoflurane or isoflurane in concentrations of $0.65 \mathrm{MAC}$ in nitrous oxide as their primary anaesthetic agent. Patients were excluded if they were pregnant, had a medical history of CNS disease (anticipated potential for increased intracranial pressure), or muscle disease, or if they had received a general anaesthetic within the preceding seven days. A complete medical history, physical examination, and baseline laboratory studies (haematology, chemistry, and renal and liver function tests) were performed preoperatively.

\section{Conduct of anaesthesia}

Heart rate, arterial blood pressure, temperature and res- piratory rate were recorded before anaesthesia. The subjects received no preanaesthetic medication until after they had arrived in the operating room suite. Intraoperatively, all patients were monitored by continuous ECG (lead II), an automated oscillometric blood pressure system (SpaceLabs Model 90430), pulse oximeter, and an oesophageal temperature probe. After breathing $100 \%$ oxygen for a minimum of three minutes, anaesthesia was induced using fentanyl $\left(1-2 \mu \mathrm{g} \cdot \mathrm{kg}^{-1} i v\right)$, thiopentone (3-5 $\left.\mathrm{mg} \cdot \mathrm{kg}^{-1} \dot{i}\right)$, and succinylcholine $\left(1.5-2.0 \mathrm{mg} \cdot \mathrm{kg}^{-1}\right.$ iv). Following tracheal intubation, anaesthesia was maintained with $60 \%$ nitrous oxide in oxygen and the predetermined end-tidal concentration of either 0.65 MAC (1.3\%) sevoflurane or $0.65 \mathrm{MAC}(0.8 \%)$ isoflurane for the duration of surgery. Anaesthetic concentrations were kept as constant as possible. Brief adjustments were permitted in response to drastic changes in haemodynamic variables ( $>30 \%$ change from baseline). However, the initial response to this degree of hypotension was intravascular volume expansion, or a small dose of a vasopressor (5-15 mg ephedrine $\dot{i}$ or 30-100 $\mu$ g phenylephrine $\dot{v}$ ), or both. Neuromuscular blockade was provided using incremental doses of atracurium or vecuronium if deemed necessary by the investigator, with the dosage guided by peripheral nerve stimulation. Anaesthetic gases were delivered with a North American Drager Anesthesia Machine (Model 2A) (Telford, Pennsylvania) using a circle system and Sodasorb $\mathrm{CO}_{2}$ absorber (W.R. Grace and Co., Lexington, Mass.). Using fresh gas flows of $\geq 5$ $L \cdot \min ^{-1}$, ventilation was controlled and adjusted to maintain $\mathrm{PETCO}_{2}$ between 30 and $35 \mathrm{mmHg}$. End-tidal anaesthetic gas concentrations were measured with a Datex Ultima Multigas Analyzer (Datex Medical Instrumentation, Inc., Tewksbury, Mass.). This was calibrated using prepared standard gas concentrations. The vaporizers used were a North American Drager vaporizer specially calibrated for use with sevoflurane and a North American Drager Vapor 19.1 vaporizer for isoflurane.

\section{Recording of data}

A trained, independent observer who was not administering the anaesthetic recorded data throughout the preoperative, operative, emergence, and recovery periods. Heart rate and blood pressure measurements were recorded every minute starting one minute before induction and extending through the first $15 \mathrm{~min}$ of anaesthesia and continuing, if necessary, every five minutes until incision. At surgical incision, measurements were again made every minute for five minutes and continued thereafter every five minutes until emergence from anaesthesia.

Approximately five minutes before the end of surgery, residual neuromuscular blockade was reserved with neostigmine $\left(40 \mu \mathrm{g} \cdot \mathrm{kg}^{-1} \dot{w}\right)$ and glycopyrrolate $\left(10 \mu \mathrm{g} \cdot \mathrm{kg}^{-1}\right.$ 
$\dot{w})$. The maintenance end-tidal concentrations of anaesthetic gases were continued until the completion of surgery (closure of wound) and then nitrous oxide and the volatile agent were discontinued simultaneously with no tapering. At this time the lungs were manually ventilated with $100 \% \mathrm{O}_{2}$ at a fresh gas flow of $6 \mathrm{~L} \cdot \mathrm{min}^{-1}$, maintaining the $\mathrm{PETCO}_{2}$ between 30 and $35 \mathrm{mmHg}$ until spontaneous ventilation resumed. From the time that the anaesthetic gases were turned off until a positive response was obtained, the patients were asked, at least once every minute, in a normal tone of voice to open their eyes and to squeeze the observer's hand. The response times for each of these requests, the timing of extubation, and the return of purposeful movement were all recorded in relation to discontinuation of the anaesthetic. Following extubation patients were questioned at least every one to two minutes regarding orientation by asking them their name, birthdate, and location. Both in the postanaesthetic care unit (PACU) and following transfer to the ward the independent observer monitored subjects for a minimum of two hours for nausea and vomiting, requests for analgesic medication, and vital signs. The incidence of nausea, vomiting, and untoward side effects was recorded for a further $22 \mathrm{hr}$ by combining information from ward nurses and that obtained at interviews with subjects 24 hr after anaesthesia.

\section{Data analysis}

Data are expressed as mean values \pm standard error (SE). Demographic data were analyzed using unpaired Student's $\mathbf{t}$ tests. Cardiovascular data were analyzed for between group differences using unpaired Student's $t$ tests corrected by Bonferroni's method for multiple comparisons, and for within-group differences using repeated measures of analysis of variance; Scheffe's $F$ test was then used to compare specific differences. Multivariate regression analysis was used to determine the effects of age and anaesthetic exposure on emergence times. Chisquare analysis was used to compare differences in categorical variables (e.g., incidence of nausea and vomiting). In all cases, $P<0.05$ was considered significant.

\section{Results}

\section{Subjects}

Of the 51 patients enrolled in the study, 50 were included for analysis. One patient was withdrawn from the study after randomization and induction of anaesthesia when initial attempts at tracheal intubation were unsuccessful. Awake nasotracheal intubation (a protocol violation) was necessary to secure the airway. The two groups were comparable with respect to age, weight, sex distribution, and ASA classification of physical status. In addition, the
TABLE I Patient data

\begin{tabular}{lll}
\hline & Sevoflurane & Isoflurane \\
\hline Number of patients & 24 & 26 \\
(M = male, F = female) & (M 8, F 16) & (M 12, F 14) \\
Age (yr) & $45.1 \pm 3.1$ & $51.0 \pm 2.8$ \\
Weight (kg) & $79.9 \pm 3.2$ & $77.4 \pm 3.3$ \\
ASA physical status & & \\
$\quad$ (I/II/III) & $9 / 15 / 0$ & $6 / 16 / 4$ \\
Procedures & 11 & 10 \\
- Orthopaedic & 5 & 8 \\
- Gynaecological & 4 & 6 \\
- General surgery & $3 / 1$ & $1 / 1$ \\
- ENT/Ophthalmological & $283 \pm 97$ & $205 \pm 34$ \\
Estimated blood loss (ml) & $2019 \pm 187$ & $2029 \pm 160$ \\
Fluid replacement (ml) & & \\
\hline
\end{tabular}

Except where noted values are mean $\pm S E$. No differences were found between sevoflurane and isoflurane.

procedures performed and the associated intraoperative fluid losses and replacement were similar for the two groups (Table I).

\section{Haemodynamic data}

There were no differences between the groups with regard to baseline measurements of systemic blood pressures (Figure 1). With the exception of systolic pressures in the isoflurane group which were within baseline range, blood pressure readings in both groups were increased from baseline levels at induction and for several minutes thereafter. Four minutes after tracheal intubation, both systolic and diastolic arterial blood pressures had fallen to within the baseline range in both groups. From this point until surgical incision mean systolic and diastolic pressures remained below baseline levels for both groups. Despite these similar trends, diastolic pressures were decreased an average of $10 \mathrm{mmHg}$ in the sevoflurane group; this was different from the average reduction in diastolic pressure of $3 \mathrm{mmHg}$ observed in the isoflurane group at this time $(P=0.0248)$. The mean interval from intubation to incision did not differ between the groups (24.3 $\pm 1.3 \mathrm{~min}$ in the sevoflurane group versus 25.0 $\pm 1.3 \mathrm{~min}$ in the isoflurane group). Five patients in the sevoflurane group and four patients in the isoflurane group received treatment for hypotension during this period. Therapy in all cases consisted of either pharmacological support (30-100 $\mu \mathrm{g}$ phenylephrine or 5-15 mg ephedrine $i v$ ) or intravascular volume expansion, or both. One minute after surgery was initiated systolic and diastolic arterial pressures in both groups were below their baseline values. The systolic pressures measured in the sevoflurane patients averaged $10 \mathrm{mmHg}$ lower than those of the isoflurane patients $(P=0.05)$. This disparity was not evident in the diastolic measurements. However, after 


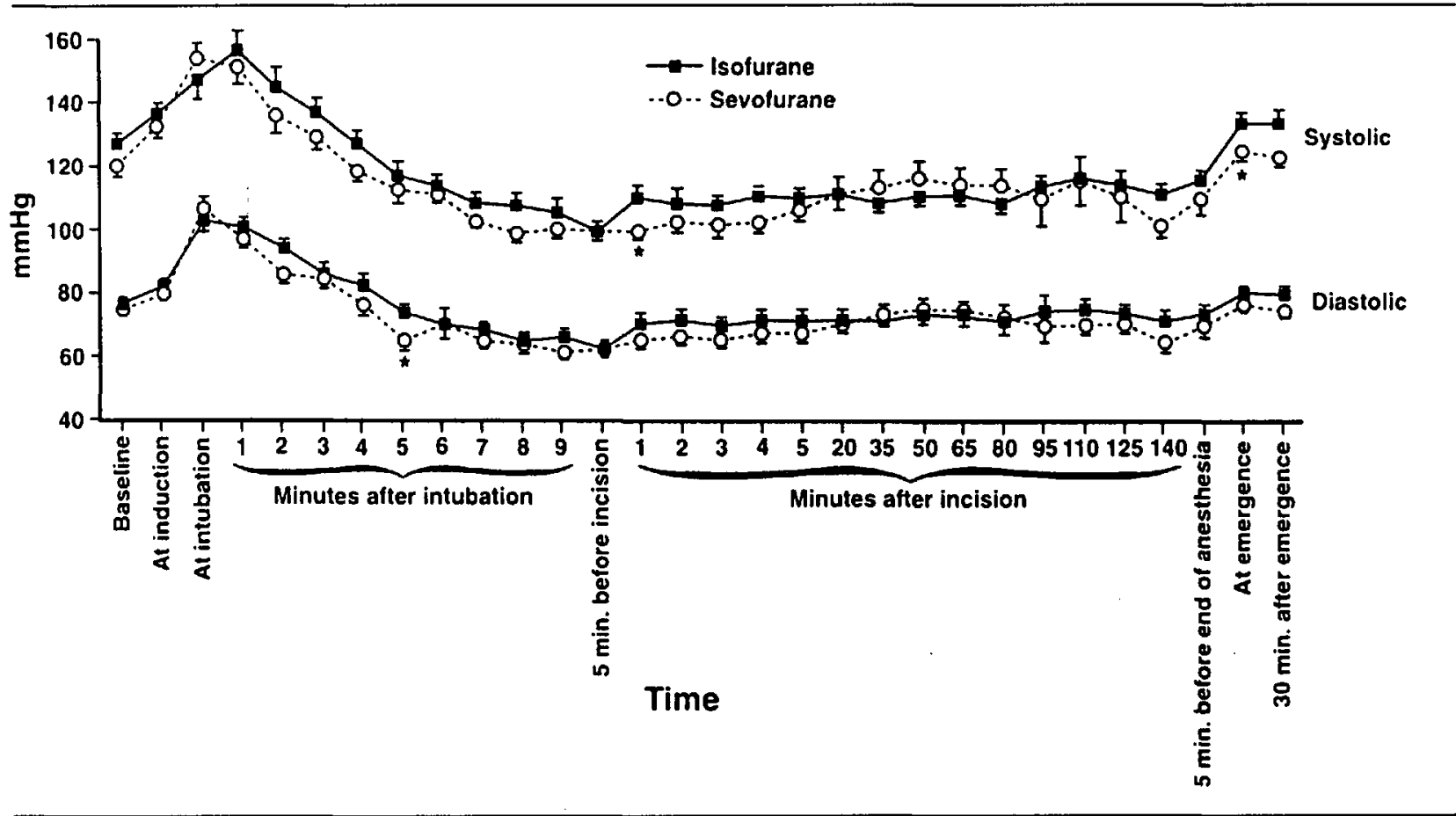

FIGURE 1 Mean (SE) systolic and diastolic blood pressure during anaesthesia and recovery. $* P<0.05$ vs corresponding isoflurane values.

20 min of surgery systolic and diastolic arterial pressures in the sevoflurane group had recovered to within baseline range and remained so until shortly before emergence from anaesthesia. In comparison, systolic and diastolic pressures in the isoflurane group continued to be lower than baseline for $85 \mathrm{~min}$ after surgery had begun. At patients emergence from anaesthesia (time at which patient first opened their eyes on command) blood pressures did not differ from baseline for all patients; however, systolic pressures in the sevoflurane group were lower ( 9 $\mathrm{mmHg}$ ) than those in the isoflurane group $(P=0.02)$. Thirty minutes after emergence from anaesthesia blood pressure measurements were the same as baseline values with no differences evident between sevoflurane and isoflurane patients.

Heart rate did not differ between patients receiving sevoflurane and isoflurane for the duration of the study (Figure 2). Eight minutes after tracheal intubation, heart rate had decreased below baseline in the sevoflurane group only $(P=0.0116)$. At surgical incision heart rate averaged $8-9$ beats per minute lower than baseline in both groups $(P<0.006)$. Following incision, however, heart rate trends followed reverse trends. In the isoflurane group heart rate followed a gradual decline from baseline after the start of surgery. In contrast, heart rate in the sevoflurane group gradually increased to within baseline range after $35 \mathrm{~min}$ of surgery.

\section{Recovery data}

Recovery from anaesthesia, as determined by eye opening in response to vocal request, time to extubation after discontinuation of anaesthetic agents, a positive response to appropriate commands or purposeful movement, and demonstration of appropriate orientation was faster with sevoflurane than with isoflurane in spite of comparable anaesthetic duration and dose (Table II). Furthermore, a positive correlation was found between total anaesthetic exposure or dose (MAC hours) and emergence time in the isoflurane group $(r=0.517, P=0.028)$ but not in the sevoflurane group. The age of the patient was shown to have different effects on recovery according to which agent had been used. A positive correlation of emergence time with age was found in the sevoflurane group ( $r=0.537, P=0.028$ ) but not in the isoflurane group.

In spite of more rapid emergence from the effects of anaesthesia, postoperative analgesia was not required any sooner for subjects in the sevoflurane group than for those in the isoflurane group (Table II). Pain relief was first administered after a mean interval of $46.8 \pm 14.6 \mathrm{~min}$ from discontinuation of the anaesthetic agents in the sevoflurane group, and after $38.0 \pm 4.8 \mathrm{~min}$ in the isoflurane group ( $P=\mathrm{NS}$ ). The most commonly encountered postanaesthetic side effects, possibly attributable to the volatile agents used, were, in order of decreasing fre- 


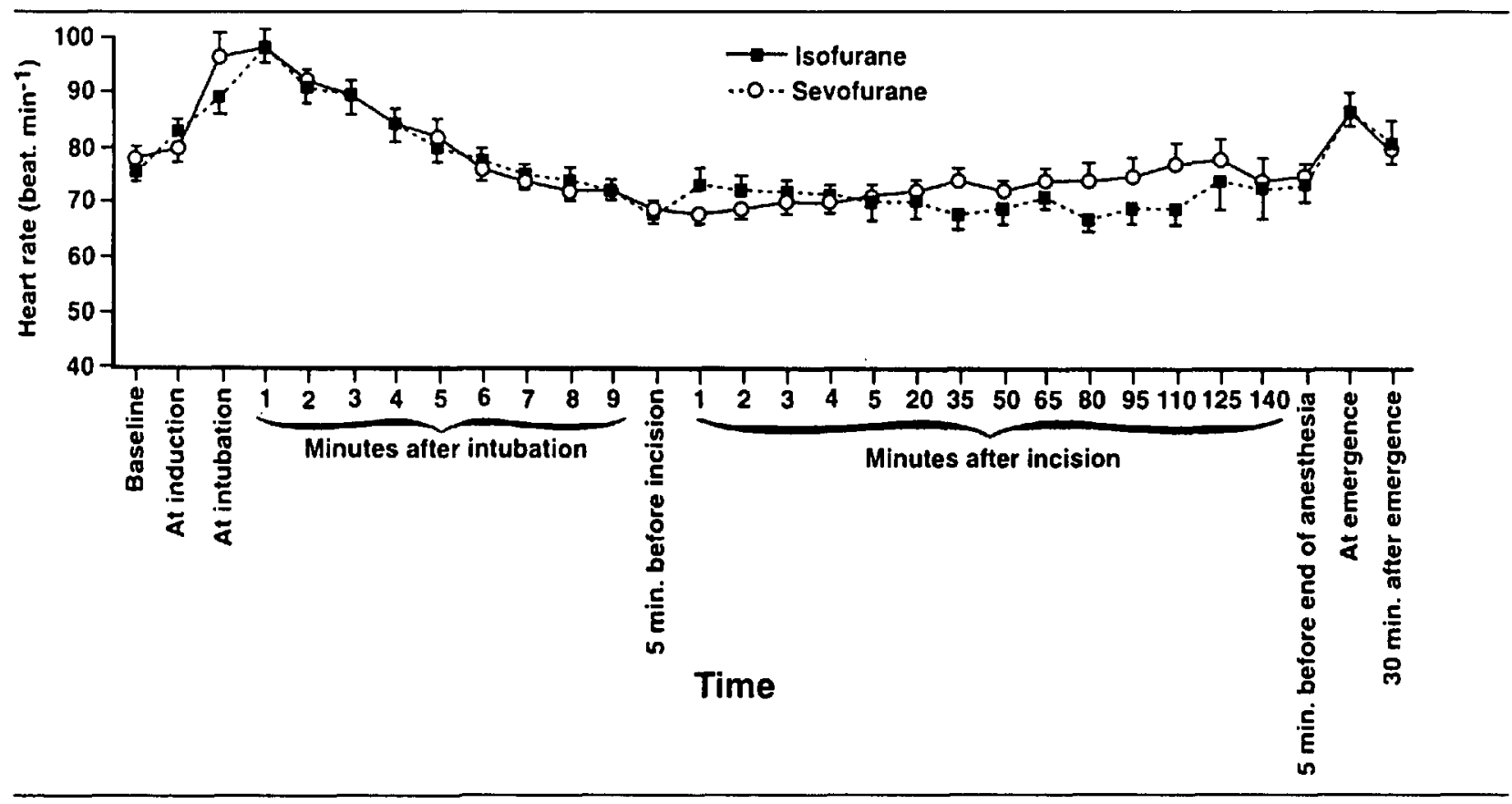

FIGURE 2 Mean (SE) heart rate during anaesthesia and recovery.

TABLE II Anaesthetic duration and timing of recovery events

\begin{tabular}{lcc}
\hline $\begin{array}{l}\text { Times in min } \\
\text { (except where noted) }\end{array}$ & Sevofurane & Isoflurane \\
\hline Anaesthetic duration & $139.0 \pm 11.7$ & $147.0 \pm 11.2$ \\
MAC hours (hr) & $1.4 \pm 0.1$ & $1.6 \pm 0.1$ \\
$\begin{array}{l}\text { Opened eyes in response to } \\
\quad \text { command }\end{array}$ & $9.9 \pm 1.1^{*}$ & $13.9 \pm 1.3$ \\
Extubation time & $9.6 \pm 1.0^{*}$ & $14.1 \pm 1.3$ \\
Able to respond to commands & & \\
$\quad \begin{array}{l}\text { appropriately/purposeful } \\
\text { movement }\end{array}$ & $10.4 \pm 1.0^{*}$ & $15.6 \pm 1.0$ \\
Orientated to name, birthdate & $14.0 \pm 1.0^{*}$ & $20.0 \pm 1.0$ \\
Time to first request for analgesia & $46.8 \pm 14.6$ & $38.0 \pm 4.8$ \\
\hline
\end{tabular}

Extubation time $=$ time to extubation after discontinuation of anaesthetic.

$* P<0.05$ vs isoflurane group.

Data shown as mean $\pm \mathrm{SE}$.

quency, somnolence, nausea, dizziness, and vomiting (Table III). The frequency of these complaints did not differ between the two groups.

\section{Discussion}

We have shown that, for the most part, clinically comparable haemodynamic effects occur during anaesthesia with 0.65 MAC sevoflurane in nitrous oxide and 0.65 MAC isoflurane and nitrous oxide. With the exception of measurements made $35 \mathrm{~min}$ after surgical incision, both systolic and diastolic arterial pressures with sevo-
TABLE III Postanaesthetic data

\begin{tabular}{lll}
\hline & Sevoflurane & Isoflurane \\
\hline $\begin{array}{l}\text { Incidence of nausea first } 24 \mathrm{hr} \\
\text { (\% of patients) }\end{array}$ & $2 / 24(8.3 \%)$ & $3 / 26(11.5 \%)$ \\
$\begin{array}{l}\text { Incidence of vomiting first } 24 \mathrm{hr} \\
\quad \text { (\% of patients) }\end{array}$ & $1 / 24(4.2 \%)$ & $0 / 26(0 \%)$ \\
$\begin{array}{l}\text { Incidence of somnolence first } 24 \mathrm{hr} \\
\text { (\% of patients) }\end{array}$ & $9 / 24(36.5 \%)$ & $11 / 26(42.3 \%)$ \\
$\begin{array}{l}\text { Incidence of dizziness first } 24 \mathrm{hr} \\
\text { (\% of patients) }\end{array}$ & $1 / 24(4.2 \%)$ & $1 / 26(3.5 \%)$ \\
\hline$P=$ NS. & & \\
& &
\end{tabular}

flurane were somewhat lower or the same as those of subjects receiving isoflurane. The more rapid decline in diastolic arterial pressure evident within five minutes of starting sevoflurane presumably is the result of a faster induction. How this pattern is attributable to differential effects of the two agents on systemic vascular resistance and cardiac output was not established. Previous work in animals has shown, however, that the cardiovascular effects of sevoflurane are similar to those of isoflurane. ${ }^{2,3}$ It is intriguing that at $35 \mathrm{~min}$ after initiation of surgery, when optimum stability of surgical anaesthesia might be expected, although systolic and diastolic arterial pressures did not differ from baseline values in either group, in the sevoflurane patients these measurements were higher than in the isoflurane group. By this same juncture, heart 
rate in the sevoflurane group had also evidenced a slow return to baseline values while heart rate in the isoflurane group remained below baseline. One might argue that $0.65 \mathrm{MAC}(1.3 \%)$ sevoflurane in nitrous oxide $(60 \%)$ was not, in fact, providing adequate or equivalent anaesthesia to $0.65 \mathrm{MAC}(0.8 \%)$ isoflurane in the same concentration of $\mathrm{N}_{2} \mathrm{O}$. It is doubtful that this was the case, however, since the MAC value of sevoflurane chosen to calculate the MAC equivalent (2.0\%) was at the higher range of published data (published values of MAC for $30-60 \mathrm{yr}$ olds range from $1.7-2.05 \%){ }^{9,10}$ Further, it has been determined that $0.66 \%$ sevoflurane in $63.5 \% \mathrm{~N}_{2} \mathrm{O}$ is equivalent to $1 \mathrm{MAC}^{9}$ and that the anaesthetic $\mathrm{ED}_{95}$ for sevoflurane in the same concentration of $\mathrm{N}_{2} \mathrm{O}$ is $0.94 \%$, ${ }^{9}$ making it unlikely that, at the concentration of sevoflurane used $(1.3 \%)$, the majority of patients were inadequately anaesthetized.

As might be predicted from its lower blood/gas solubility, we also demonstrated that emergence from sevoflurane anaesthesia was more rapid than that from isoflurane. Since the conduct of anaesthesia in this study, together with the patient and surgical mix, represents conditions similar to those commonly encountered in practice, we feel that this result is of particular clinical relevance. Our data confirm that of three previous studies which have shown that faster recovery from sevoflurane anaesthesia can be expected in procedures of moderate duration provided that the use of adjuvant drugs such as opioids is not excessive. ${ }^{46}$ In comparing sevoflurane and isoflurane in a younger, healthier, more homogeneous patient population, Frink $e t$ al. showed that emergence from sevoflurane- $\mathrm{O}_{2}$ anaesthesia could be expected in less than half the time taken after discontinuation of isoflurane- $\mathrm{O}_{2}$ anaesthesia $(7.5 \pm 0.5 \mathrm{~min}$ versus $18.6 \pm$ $2.0 \mathrm{~min}) .{ }^{4} \mathrm{It}$ is possible that our results, though still significant, show a smaller difference $(9.9 \pm 1.1 \mathrm{~min}$ versus $13.9 \pm 1.3 \mathrm{~min}$ ) in emergence times between these two volatile agents because of the compounding influence of nitrous oxide elimination. Average surgical times in our subjects were of sufficient duration to permit the relatively slow process of $\mathrm{N}_{2} \mathrm{O}$ equilibration with vessel-poor tissues, thus creating large tissue stores. Yasuda et al. have demonstrated that in this setting elimination of nitrous oxide may actually be slower than that of sevoflurane, in contradiction to what might be predicted on the basis of their blood/gas coefficients. ${ }^{11}$ Thus, continuing, slow excretion of $\mathrm{N}_{2} \mathrm{O}$ could account for the slightly longer emergence times observed in our sevoflurane patients when compared with those previously reported following sevoflurane- $\mathrm{O}_{2}$ anaesthesia. ${ }^{4}$

We have shown a positive correlation between duration of anaesthetic exposure (MAC hours) and emergence times with isoflurane which was not present with sevo- flurane. A theoretical explanation may be provided using pharmacokinetic considerations. It would appear that emergence from anaesthesia under the conditions of this study has much greater dependence on the relative solubilities of the two agents in blood and is less influenced by their affinity for tissues. Indeed, in spite of similar tissue/blood partition coefficients, accumulating depots of anaesthetic, especially in vessel-rich tissues, over time have minimal effect on emergence from sevoflurane, while prolonging that from isoflurane. Frink et al. also observed that awakening from sevoflurane was independent of anaesthetic duration; these observations followed even greater anaesthetic exposure $(2.5 \pm 1.1 \mathrm{hr})$ than those in our patients $(1.4 \pm 0.1 \mathrm{hr}){ }^{4}$

We also found that recovery following sevoflurane anaesthesia was closely linked to age. This is not surprising when considering the established negative correlation of MAC and MAC-awake of sevoflurane with age. ${ }^{13,14}$ Less easily explained, however, is why the same correlation was not evident for isoflurane. Again, perhaps the differing blood/gas solubilities of sevoflurane and isoflurane can provide an explanation. On cessation of sevoflurane rapid alveolar washout occurs, aided by the relative insolubility of the agent in blood. The characteristics of this rather steep washout curve may allow age differences in MAC-awake to be temporally different from those resulting from the more gradual slope of isoflurane alveolar washout. While it is doubtful that sevoflurane metabolism produces clinically important effects, it is theoretically possible that age-related decreases in metabolism of sevoflurane may also have contributed to the negative correlation of age and emergence times.

Although patients recovered faster following sevoflurane anaesthesia, this was not associated with earlier requests for postoperative analgesia. The procedures were of sufficient duration to make it unlikely for the opioid given at induction to have been an appreciable factor at emergence. Isoflurane, desflurane, and sevoflurane are all thought to be potent amnestics and thus, by extrapolation, potent analgesics at relatively low alveolar concentrations (0.3 MAC). Unlike desflurane, however, sevoflurane has tissue/blood partition coefficients quite similar to isoflurane and even halothane ${ }^{14}$ After rapidly achieving MAC-awake levels of sevoflurane, perhaps continued, low level redistribution of the agent from tissue stores is adequate to provide some analgesia in the early postoperative period. Since, during desflurane anaesthesia, minimal desflurane is sequestered in tissues, it might be interesting to compare postoperative analgesic requirements following desflurane and sevoflurane anaesthesia to see if this theory holds merit.

Knowledge of how the specific attributes of sevoflurane can benefit patient care will undoubtedly accompany ex- 
panded clinical use. The commercial availability of sevoflurane does appear to be imminent as lingering uncertainties about the drug's safety diminish. Although some still advocate caution, ${ }^{15}$ recent evidence suggests that the potential for toxicity resulting from the interaction of sevoflurane with $\mathrm{CO}_{2}$ absorbants is minimal. Even under clinical conditions favourable for the formation of degradation products, low-flow anaesthesia with fresh baralyme absorbant and high ambient temperatures, Frink et al. ${ }^{16}$ has shown that only one byproduct is detectable, and in insufficient quantities to be an important safety threat. Further, the established record of clinical safety in Japan where sevoflurane has now been administered to over one million patients, is supportive of an anaesthetic agent with an acceptable safety profile.

In conclusion, we have demonstrated that sevoflurane is associated with comparable haemodynamic stability but provides more rapid emergence than isoflurane when administered with nitrous oxide to surgical patients under clinical conditions. Our data suggest that sevoflurane may offer some advantages over currently used volatile anaesthetics.

\section{References}

1 Brown BR Jr, Frink EJ Jr. Whatever happened to sevoflurane? (Editorial). Can J Anaesth 1992; 39: $207-9$.

2 Wallin RF, Regan BM, Napoli MD, Stern IJ. Sevoflurane: a new inhalational anesthetic agent. Anesth Analg 1975; 54: 758-66.

3 Holaday DA, Smith FR. Clinical characteristics and biotransformation of sevoflurane in healthy human volunteers. Anesthesiology 1981; 54: 100-6.

4 Frink EJ Jr, Malan TP, Atlas M, Dominguez LM, DiNardo JA, Brown BR Jr. Clinical comparison of sevoflurane and isoflurane in healthy patients. Anesth Analg 1992; 74: 241-5.

5 Smith I, Ding $Y$, White PF. Comparison of induction, maintenance, and recovery characteristics of sevoflurane$\mathrm{N}_{2} \mathrm{O}$ and propofol-sevoflurane- $\mathrm{N}_{2} \mathrm{O}$ with propofolisoflurane- $\mathrm{N}_{2} \mathrm{O}$ anesthesia. Anesth Analg 1992; 74: 253-9.

6 Quinn AC, Newman PJ, Hall GM, Grounds RM. Sevoflurane anaesthesia for major intra-abdominal surgery. Anaesthesia 1994; 49: 567-71.

7 Crawford MW, Lerman J, Pilato M, Orrego H, Saldivia V, Carmichael FJ. Haemodynamic and organ blood flow responses to sevoflurane during spontaneous ventilation in the rat: a dose-response study. Can J Anaesth 1992; 39: 270-6.

8 Navarro R, Weiskopf RB, Moore MA, et al. Humans anesthetized with sevoflurane or isoflurane have similar arrhythmic response to epinephrine. Anesthesiology 1994; 80: 545-9.

9 Katoh T, Ikeda K. The minimum alveolar concentration
(MAC) of sevoflurane in humans. Anesthesiology 1987; 66: 301-3.

10 Scheller MS, Saidman LJ, Partridge BL. MAC of sevoflurane in humans and the New Zealand white rabbit. Can J Anaesth 1988; 35: 153-6.

11 Yasuda N, Lockhart SH, Eger EI II, et al. Comparison of kinetics of sevoflurane and isoflurane in humans. Anesth Analg 1991; 72: 316-24.

12 Katoh T, Suguro Y, Nakajima R, Kazama T, Ikeda K. Blood concentrations of sevoflurane and isoflurane on recovery from anaesthesia. Br J Anaesth 1992; 69: 259-62.

13 Katoh T, Suguro Y, Ikeda T, Kazama T, Ikeda K. Influence of age on awakening concentrations of sevoflurane and isoflurane. Anesth Analg 1993; 76: 348-52.

14 Yasuda N, Targ AG, Eger EI II. Solubility of I-653, sevoflurane, isoflurane, and halothane in human tissues. Anesth Analg 1989; 69: 370-3.

15 Mazze RI. The safety of sevoflurane in humans (Editorial). Anesthesiology 1992; 77: 1062-3.

16 Frink EJ JR, Malan TP, Morgan SE, Brown EA, Malcomson $M$, Brown $B R$ Jr. Quantification of the degradation products of sevoflurane in two $\mathrm{CO}_{2}$ absorbants during low-flow anesthesia in surgical patients. Anesthesiology 1992; 77: 1064-9. 